\section{National Preparedness Month - September 2017}

Every September, CDC, private and public health institutions, and approximately 3,000 government organizations support preparedness efforts and encourage Americans to take action before, during, and after an emergency. Every community in the United States should be ready to respond to an infectious disease outbreak, chemical or radiological release, or natural disaster (1). Public health systems should have the capacity to scale up and respond to the varying demands of public health emergencies (2).

Many emergencies happen without warning; it is important for all persons to take steps ahead of time to keep themselves and their loved ones safe and healthy. Research shows that only $46 \%$ of persons think a natural disaster is likely to occur in their community (3). It is vital to take immediate and appropriate actions in the event of an emergency.

This year, CDC's Office of Public Health Preparedness and Response focuses on empowering individuals to better prepare for public health emergencies. The 2017 theme "The Power of Preparedness" highlights the importance of building and updating an emergency kit, having and reviewing an emergency plan, inspiring others to prepare, and taking immediate action to save lives. This issue of $M M W R$ includes a report describing a series of unannounced mystery patient drills that were conducted in New York City emergency departments to assess response to potential infectious disease threats. Individual and community preparedness resources are available at https://www.cdc.gov/phpr/preparedness_month.htm.

\section{References}

1. CDC. In an emergency you can't respond effectively if you are not ready. Atlanta, GA: US Department of Health and Human Services, CDC; 2017. https://www.cdc.gov/phpr/whatwedo/emergency.htm

2. Redd SC, Frieden TR. CDC's evolving approach to emergency response. Health Secur 2017;15:41-52. https://doi.org/10.1089/hs.2017.0006

3. Federal Emergency Management Agency. Preparedness in America. Washington, DC: US Department of Homeland Security, Federal Emergency Management Agency; 2014. https:/www.fema.gov/ media-library-data/1409000888026-1e8abc820153a6c8cde24ce4 2c16e857/20140825_Preparedness_in_America_August_2014_ Update_508.pdf

\section{Assessment of Hospital Emergency Department Response to Potentially Infectious Diseases Using Unannounced Mystery Patient Drills - New York City, 2016}

Mary M.K. Foote, $\mathrm{MD}^{1}$; Timothy S. Styles, MD ${ }^{1,2}$; Celia L. Quinn, MD ${ }^{1,2}$

Recent outbreaks of infectious diseases have revealed significant health care system vulnerabilities and highlighted the importance of rapid recognition and isolation of patients with potentially severe infectious diseases. During December 2015-May 2016, a series of unannounced "mystery patient drills" was carried out to assess New York City Emergency Departments' (EDs) abilities to identify and respond to patients with communicable diseases of public health concern. Drill scenarios presented a patient reporting signs or symptoms and travel history consistent with possible measles or Middle East Respiratory Syndrome (MERS). Evaluators captured key infection control performance measures, including time to patient masking and isolation. Ninety-five drills (53 measles and 42 MERS) were conducted in 49 EDs with

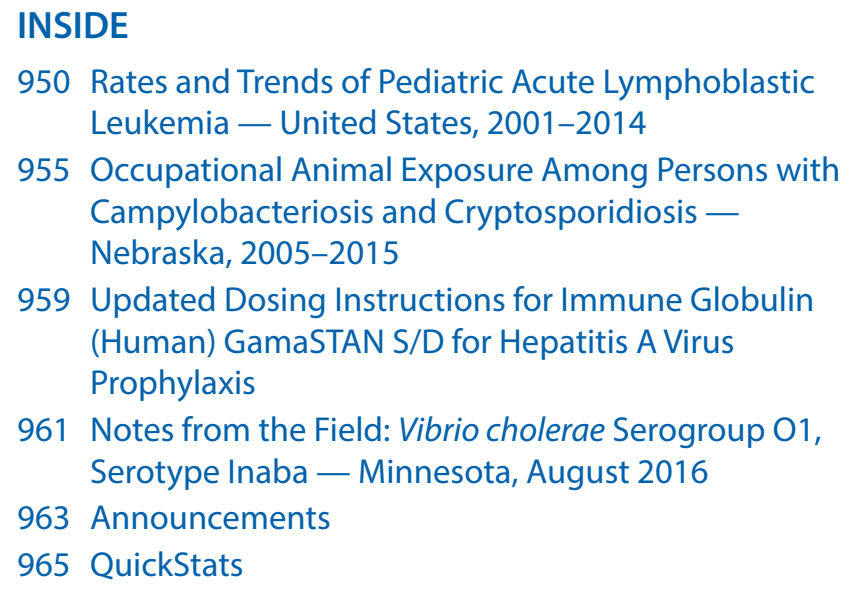

950 Rates and Trends of Pediatric Acute Lymphoblastic Leukemia — United States, 2001-2014

955 Occupational Animal Exposure Among Persons with Campylobacteriosis and Cryptosporidiosis Nebraska, 2005-2015

959 Updated Dosing Instructions for Immune Globulin (Human) GamaSTAN S/D for Hepatitis A Virus Prophylaxis

961 Notes from the Field: Vibrio cholerae Serogroup 01, Serotype Inaba - Minnesota, August 2016

963 Announcements

965 QuickStats

Continuing Education examination available at https://www.cdc.gov/mmwr/cme/conted_info.html\#weekly.

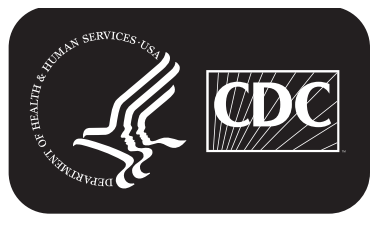

U.S. Department of Health and Human Services

Centers for Disease Control and Prevention 